\title{
INTERCEPTAÇÃO TELEFÔNICA E SUA ADMISSIBILIDADE CONSTITUCIONAL
}

\author{
Telephone interception and its constitutional admissibility
}

\section{Uelinton Damasio Lopes ${ }^{1}$ Thiago Jordace ${ }^{2}$}

\author{
${ }^{1}$ Bacharel em Direito pela UNISUAM - Rio \\ de Janeiro (RJ).
}

2 Professor e advogado; Pós doutorando pela UERJ - Rio de Janeiro (RJ);

\section{Autor correspondente:}

Thiago Jordace

E-mail: jordace@jordacemedero.com

\section{Como citar este artigo:}

LOPES, U.D.; JODARCE, T. Intercepção telefônica e sua admissibilidade constitucional. Revista Saber Digital, v. 14, n. 2, p. 08-24, 2021.

\section{RESUMO}

O presente trabalho tratará sobre a Interceptação Telefônica e sua Admissibilidade das Provas Produzidas e, irá analisar, tanto na doutrina quanto na Jurisprudência, a aplicabilidade da Lei, com base nos Direitos Fundamentais e nos Princípios, buscando os requisitos para a concessão da interceptação, quais os meios de provas obtidas e, se é possível à utilização de provas ilícitas no Direito Processual Penal Brasileiro. As provas são obtidas para que o juiz possa se convencer, bem como exercer o que está positivado em lei. Em muitos processos, as provas obtidas são ilícitas, fazendo com que os Processos sejam morosos em vez de céleres e, até mesmo, casos em que o Magistrado prolate uma sentença injusta, visto que se convenceu por uma prova ilícita apresentada nos autos. A finalidade da Interceptação Telefônica se trata da investigação criminal, ou, a instrução processual penal e, deverá observar a forma que a lei estabelecer para a sua realização. A Interceptação Telefônica constitui um importante meio para a obtenção de prova no Processo Penal tanto na fase preparatória como também na fase incidental do processo. Portanto, a justificativa em se estudar sobre o assunto em tela se verifica através dos diferentes desafios nos Centros de cumprimento de medidas a serem utilizadas em uma investigação, nos quais são locais de produção e, reprodução de crimes, em particular as questões, no caso específico, de provas lícitas e ilícitas em um processo.

Palavras-chave: Intercepção telefônica; Admissibilidade; Constitucionalidade.

\section{ABSTRACT}

The present work will deal with Telephone Interception and its Admissibility of the Evidence Produced and will analyze, both in doctrine and in Jurisprudence, the applicability of the Law, based on Fundamental Rights and Principles, seeking the requirements for granting the interception, which the means of evidence obtained and, if it is possible to use illicit evidence in Brazilian Criminal Procedural Law. Evidence is obtained so that the judge can be convinced, as well as exercise what is established by law. In many cases, the evidence obtained is illicit, making the Proceedings time consuming instead of swift and, even, cases in which the Magistrate extends an unjust sentence, since he was convinced by an illicit evidence presented in the case file. The purpose of Telephone Interception is criminal investigation, or criminal procedural instruction, and must observe the form that the law establishes for its realization. Telephone Interception is an important means of obtaining evidence in the Criminal Procedure both in the preparatory phase and also in the incidental phase of the process. Therefore, the justification for studying the subject in question is verified through the different challenges in the fulfillment of measures to be used in an investigation, in which they are places of production and, reproduction of crimes, in particular the issues, in the case specific, of legal and illegal evidence in a process.

Keywords: Telephone Interception; Admissibility; Evidence produced. 


\section{INTRODUÇÃO}

Consiste a Interceptação telefônica na gravação de um conteúdo de uma comunicação telefônica, onde está se dá entre dois, ou mais sujeitos, esta interceptação é realizada por uma terceira pessoa sem que os demais sujeitos estejam cientes da captação da conversa.

Este meio de prova ocorre por intermédio de captação de um conteúdo de uma comunicação telefônica, onde está se dá entre dois, ou mais sujeitos, realizada por uma terceira pessoa sem que os demais sujeitos estejam cientes da captação da conversa.

A partir da Constituição Federal de 1988 foi estabelecido no artigo $5^{\circ}, \mathrm{X}$, o direito a intimidade e privacidade, mas, em relação às interceptações telefônicas, permaneceu uma lacuna, pois ainda, eram utilizadas maneiras diferentes de se pensar, como também de agir quanto ao tema.

A Lei o 9.296, criada em 24 de julho de 1996, surgiu com a finalidade de disciplinar a a interceptação telefônica por ser um importante meio para a obtenção de prova no Processo Penal. Está pode ser levada a efeito na fase preparatória como também na fase incidental do processo.

Esta também se trata de uma restrição a um direito fundamental, "o direito à intimidade da pessoa interceptada", como também o direito com as quais esta pessoa se relaciona.

Estabeleceu também a Lei Federal № 9.296/96 que a autorização para a quebra do sigilo telefônico está reservada à decisão judicial e, somente será decretada para fins de investigação criminal, bem como na instrução processual penal.

Dessa forma, a validade da Interceptação Telefônica, como meio para a obtenção de prova, não prescinde somente da observância aos requisitos que estão contidos na Lei ํㅜ 9.296/96.

Mas, também prescinde aos Princípios Constitucionais do Devido Processo Legal, da Proporcionalidade, bem como da Inadmissibilidade das 
Provas llícitas, pois, apenas, Regras e Princípios que são Normas Constitucionais possuem a aptidão de fundamentar a restrição a um Direito Fundamental.

A finalidade da Interceptação Telefônica se trata da investigação criminal, ou, a instrução processual penal, observará a forma que a lei estabelecer a sua realização.

O fato investigado na Interceptação Telefônica deve constituir infração penal punida com reclusão, sendo exigível a existência de indícios razoáveis acerca da autoria, ou participação, ou, ainda, quando a prova não puder ser feita por outros meios.

Haverá a inadmissibilidade da Interceptação Telefônica, quando estiverem ausentes indícios razoáveis da autoria, bem como da participação em infração penal, ou, ainda, quando a prova puder ser obtida por outras maneiras legalmente previstas.

Pode-se verificar que existem na realidade equipamentos especiais no âmbito das Polícias Federal e Civil, como também na Agência Brasileira de Inteligência $(A B I N)$, bem como na Polícia Rodoviária Federal, no Senado Federal, no Ministério Público Federal (MPF) na Câmara dos Deputados.

E, no Exército, tendo seu uso também nas Empresas privadas, estes equipamentos são utilizados nos dias atuais, sem que haja um controle do Estado para interferir acerca dessas Interceptações Telefônicas.

Portanto, a Interceptação Telefônica deferida pelo juiz deverá estar devidamente fundamentada, bem como deverá ter indícios de materialidade em infração penal para se determinar a quebra do sigilo telefônico.

E, estando devidamente autorizada por Juízo competente a Interceptação Telefônica admitirá compartilhamento com o intuito de instruir procedimento criminal, bem como procedimento administrativo disciplinar em relação aos investigados. 


\section{ESTUDO HISTÓRICO DA INTERCEPTAÇÃO TELEFÔNICA}

\subsection{Transformação Histórica}

$\mathrm{Na}$ Constituição Federal de 1969 estava disposto em seu artigo 153, § $9^{\circ}$, acerca da "inviolabilidade das comunicações telefônicas", sem qualquer exceção, mas, existia uma exceção prevista em Lei ordinária, ou seja, Lei no 4117/62, artigo 57, X, "e" (Código Brasileiro de Telecomunicações).

E, esse referido Código admitia a utilização da Interceptação Telefônica para fins processuais penais, porém, para investigação criminal, não era possível o uso da Interceptação Telefônica.

Entretanto, havia uma controvérsia entre a CRFB/69 e, o Código Brasileiro de Telecomunicações (CTB) em relação ao fato de que a Interceptação Telefônica não era recepcionada por esse Código.

Com a promulgação da Constituição Federal de 1988 se dispôs em seu artigo $5^{\circ}$, XII, sobre se admitir a Interceptação Telefônica em processo penal, bem como sua utilização nas investigações criminais, tendo sua aplicabilidade imediata e, sua eficácia limitada.

No entanto, nessa época ainda não havia uma Lei específica para tratar sobre a Interceptação Telefônica e, por isso foram criadas duas suposições para se tratar acerca do tema.

Uma posição, ou seja, uma primeira corrente que obteve prevalência no Supremo Tribunal Federal, bem como também no Superior Tribunal de Justiça (STJ) de que não deveria ser concedida a Interceptação telefônica.

Já uma segunda corrente esclarecia que a Constituição Federal de 1988 recepcionou o artigo 57 do Código Brasileiro de Telecomunicações (CBT) e, defendia que se o Magistrado autorizasse o uso da Interceptação Telefônica, esta somente poderia ser utilizada no Processo Penal, sem poder utilizar no âmbito da Interceptação Telefônica para investigação criminal.

No ano de 1996 com o advento da Lei № 9296/96 houve a regulamentação do artigo $5^{\circ}$, XII, da CRFB/88 que aborda sobre a Interceptação Telefônica, 
admitia que se tivesse a autorização do Magistrado competente, ou seja, o juiz principal do processo-crime, esta teria ainda que se enquadrar em duas hipóteses.

As hipóteses em que poderia ser utilizada a Interceptação telefônica seriam no Processo Penal, bem como nas investigações criminais e, interceptar conversa telefônica se trata do ato de se ouvir conversas de 2 (duas), ou, mais pessoas e, uma terceira pessoa esteja gravando a conversa.

Em relação aos requisitos para a liberação da Interceptação Telefônica está elencado na Lei ํㅜ 9.296/96 em seu artigo 2º , incisos e, parágrafo único, que deverão estar coerentes, bem como demonstrar clareza em relação ao pedido da autoridade policial, como também do Ministério Público (MP), pois, se não for dessa forma este pedido será negado.

Em seu âmbito a Lei n 9.296/96 esclarece como deverão ocorrer as Interceptações telefônicas, em quais hipóteses serão admitidas essas interceptações, como também definiu acerca dos requisitos necessários e, que se for utilizada dessa forma descrita na lei será aceita a utilização desta como prova.

Frise-se que, se a Interceptação Telefônica for utilizada de forma incorreta, ou seja, não expressa na Lei, esta não terá validade jurídica alguma e, desta maneira será considerada ilícita.

No tocante aos sujeitos passivos da Interceptação Telefônica a lei não especifica e, poderá ser o indiciado na (fase policial), o réu na (fase judicial), bem como a vítima, a testemunha, o informante, o delator, ou, mesmo qualquer outra pessoa física, ou jurídica, a autoridade pública, ou, particular, sempre com vistas ao objeto da diligência.

Não será observada a proibição da Interceptação Telefônica quando o advogado, o médico, bem como o padre forem corréus, com o pretexto de servirem função, ou o Ministério.

Estes serão considerados, como sendo coautores, ou, partícipes de crimes e, pode - se citar como exemplo: o advogado quando entra em um 
presídio e, depois de conversar com seu cliente, vai embora e, logo em seguida, via telefone celular, começa a fazer contatos para distribuição de entorpecentes.

Portanto, nesse caso, o Magistrado poderá com uma autoria certa interceptar o telefone deste advogado, pois, não está agindo no limite de sua função e, sim, criminosamente.

Já concernente aos sujeitos ativos da Interceptação Telefônica quem poderá requerer a Interceptação Telefônica é a autoridade Policial, o Ministério Público (MP) e, também o querelante, quando o crime de Ação Penal Privada for doloso, punido com reclusão e, outros requisitos.

A Interceptação Telefônica é cabível na Ação Penal Privada, onde, podemos citar como exemplo: o crime de pedofilia, o crime de estupro, o atentado violento ao pudor e, também no âmbito de outros crimes.

Em relação à Interceptação Telefônica só o Magistrado poderá determinar a sua concessão e, que tanto a autoridade policial, quanto o Ministério Público (MP) não poderão fazê-lo. Contudo, esta concessão só poderá ser feita pelo juiz competente, ou seja, o juiz da ação principal e, não qualquer juiz.

Quem controla a legalidade da medida judicial, ou seja, o controle judicial é o Magistrado e, este controle é feito antes da determinação da Interceptação sendo que, em hipótese alguma, mesmo sendo em caso de urgência, poderá a autoridade policial, ou, o Ministério Público (MP) determinar a Interceptação Telefônica submetendo-a posteriormente ao controle judicial de legalidade.

Está demonstrado com clareza no artigo $4^{\circ}$, $\S 1^{1^{\circ}}$ e $2^{\circ}$ da Lei $n^{\circ}$ 9296/96 acerca da Interceptação Telefônica que, somente em caso excepcional, o Magistrado poderá conceder a Interceptação Telefônica por meio verbal, bem como terá que estar presente todos os pressupostos para que a autorização seja deferida.

E, o prazo máximo para que o Magistrado avalie, bem como decida sobre o pedido da Interceptação Telefônica será de 24(vinte e quatro) horas e, sendo ultrapassado este período de tempo, a Interceptação Telefônica não terá mais validade. 


\subsection{Previsão Legal na Constituição Federal de 1988}

O Sigilo das comunicações como disposto no art. 5º, XII, da Constituição Federal de 1988, somente pode ser quebrado quando presentes três requisitos:

- Ordem judicial autorizadora;

- Finalidade de colheita de evidências para instruir investigação criminal, ou, processo penal e;

- A existência de Lei prevendo as hipóteses em que a quebra será permitida (CAPEZ, 2019, p.322).

A Constituição Federal de 1988, quando excepcionou o Princípio do Sigilo nas hipóteses de comunicações telefônicas, não iria cometer se descuidar de permitir que aconteça a Interceptação telefônica somente no caso de conversação verbal por esse meio.

Ou seja, quando são utilizados 2 (dois) aparelhos telefônicos e, proibindoa, quando esta for pretendida com a finalidade de uma investigação criminal, bem como quando for utilizada como prova em Processo Penal, nas hipóteses mais atuais.

A exceção se dá quando se menciona "comunicações telefônicas", pois, estende-se a qualquer forma de comunicação que utilize a via telefônica como meio, ainda que, haja transferência de dados, como podemos citar o uso de modem. Se não fosse, dessa forma, somente iria bastar para burlar a permissão Constitucional, que se digitasse e, não seria necessário falar.

A Constituição Federal de 1988 ao abrir expressamente a exceção em caso da comunicação telefônica não significa que o Legislador ordinário não possa também permitir a Interceptação Telefônica na hipótese de transmissão de dados, pois, não há garantias constitucionais absolutas.

Porém, se a transmissão dos dados se der por telefone, não há que se falar em inconstitucionalidade, uma vez que, a comunicação telefônica é gênero que comporta espécies. 
A transmissão telefônica da voz, da imagem, bem como de dados e de sinais e, se forem transmitidos por telefone não existem impedimentos para que sejam interceptados.

Nas comunicações telefônicas incluem-se as transmissões de informações e, dados constantes de computadores e, telemáticos, desde que, feitas por meio de cabos telefônicos, e-mail, por exemplo.

A norma que está disposta no art. 5으. XII, da CRFB/88, só permitiu a violação do sigilo no caso das comunicações telefônicas, pois, o dispositivo apenas admitiu a violação do sigilo "no último caso", que se trata do caso das comunicações telefônicas.

A Carta Magna de 1988, somente autoriza a interceptação de comunicação telefônica, na qual não está inserida a transmissão de dados, a garantia constitucional do sigilo é a regra e, a interceptação se trata da exceção, de forma que a interpretação deve ser restritiva quanto a esta.

Ainda que feita por via telefônica a comunicação de dados, que constitui objeto da telemática pode-se dizer que esta é clara, bem como está amplamente coberta pela proteção Constitucional.

O texto ainda que pudesse ensejar alguma dúvida, é notório lembrar que, as regras que limitam os direitos e, as garantias individuais só podem ser interpretadas restritivamente.

Tanto a Interceptação stricto sensu quanto a escuta telefônica inserem-se na expressão "interceptação", que está prevista no art. $5^{\circ}$, XII, da CRFB/88, portanto, submetem-se às exigências da Lei n 9.296/96, quando forem feitas fora das hipóteses legais, ou, sem autorização judicial, não devem ser admitidas.

Por afronta ao direito à privacidade, porém, excepcionalmente, mesmo quando colhidas ilegalmente, tais evidências poderão ser aceitas em atenção ao Princípio da Proporcionalidade.

Com a entrada em vigor da Lei $n^{\circ}$ 9.296, de 24 de julho de 1996 o novo texto disciplinou a Interceptação de conversas telefônicas e, o Magistrado pode autorizar a quebra do sigilo de ofício, ou, a requerimento do membro do Ministério Público (MP), ou, autoridade policial. 
Mas, somente quando presentes os seguintes requisitos: a) indícios razoáveis de autoria, ou participação em infração penal; b) não houver outro meio de se produzir a mesma prova; e c) o fato for punido com pena de reclusão (CAPEZ, 2019, p.322).

\section{INTERCEPTAÇÃO TELEFÔNICA E SUA ADMISSIBILIDADE DAS PROVAS PRODUZIDAS}

\subsection{Finalidade da Interceptação Telefônica: Obtenção de Prova}

De modo a legitimar a decisão judicial seja frente às partes, ou à universalidade das pessoas. Como se observa na lei, a Interceptação Telefônica só vale para fins de investigação criminal, ou, instrução processual penal.

Pode-se afirmar, então, que a finalidade da Interceptação Telefônica é a de ser utilizada para os fins de investigação criminal, ou, instrução processual Penal, como dispõe a CRFB/88, a fim de obter uma prova, que se materializa num documento, ou depoimento e, que um desses meios de prova é que irá fixar os fatos no processo.

A Lei no 9.296/96 que disciplinou a interceptação telefônica ficou adstrita aos requisitos mínimos constantes da Constituição Federal de 1988, quais sejam:

- exigência de autorização judicial;

- que a Interceptação Telefônica seja realizada para fins de investigação criminal, ou instrução processual penal (CAPEZ, 2019, p.322).

Já em relação ao procedimento da Interceptação Telefônica este é de natureza cautelar, cuja medida poderá ser preparatória, se realizada antes da propositura da ação penal, ou incidental, quando realizada durante a instrução processual penal.

Se devidamente autorizada nos termos da Lei 9296/96, constitui prova 
lícita e admissível, se não autorizada, configura crime, previsto no artigo 10.

Portanto, afiguram-se possíveis observados os requisitos constitucionais e legais, a Interceptação das correspondências e, das comunicações telegráficas e, de dados, sempre que as liberdades públicas estiverem sendo utilizadas como instrumento de salvaguarda de práticas ilícitas.

\subsection{O Pedido de Interceptação Telefônica (conteúdo) e o Prazo da Interceptação Telefônica}

Não poderá exceder o prazo de 15 (quinze) dias a captação das comunicações telefônicas, bem como as telemáticas e, poderão ser renováveis por igual período em caso de comprovada necessidade esse prazo da duração máxima, como também poderá o Magistrado autorizar a Interceptação Telefônica por prazo menor.

Foi estabelecido pelo Legislador o limite de tempo e, este faz parte da Proporcionalidade em abstrato e, não seria correto autorizar a quebra do sigilo das comunicações por tempo indeterminado.

Conta-se esse prazo desde o dia que em que se iniciou a devassa e, se inclui na contagem do prazo o dia do começo, pois, trata-se de medida restritiva de direito constitucional.

A renovação da Interceptação Telefônica deverá ser feita antes do limite máximo fixado pelo Magistrado em sua decisão, para que não aconteça a solução de continuidade, ou seja, a interrupção, bem como será considerada nula a Interceptação Telefônica que ocorrer sem a devida autorização judicial que não poderá ser de "ofício".

Nas hipóteses de cometimento de delitos de grande complexidade como podemos citar: a lavagem de dinheiro, o tráfico de drogas, de difícil comprovação como a corrupção ativa e passiva e, os delitos permanentes (sequestro).

Ou, ainda, crimes praticados em continuidade delitiva, a prorrogação do prazo de 15 (quinze) dias, mesmo que sucessivamente, não pode ser 
considerada, por si só, um ato que viole os ditames do artigo $5^{\circ}$, da Lei $\mathrm{n}^{0}$ 9.296/96.

Em decisões da Primeira Turma do Supremo Tribunal Federal (STF), a legitimidade da prorrogação por um período superior a 30 (trinta) dias, ou seja, 15 (quinze dias) mais uma prorrogação foi reconhecida quando necessária e, justificada, circunstancialmente.

A utilização prolongada de métodos de investigação invasivos, especialmente se a atividade criminal for igualmente duradoura, nos casos de crimes habituais, permanentes, ou, continuados.

\section{LEGISLAÇÃO APLICÁVEL A INTERCEPTAÇÃO TELEFÔNICA}

\subsection{Críticas e a Inconstitucionalidade da Interceptação Telefônica}

Em relação à Legislação que se aplica a interceptação Telefônica podese elencar a Constituição Federal de 1988 em seu artigo 5ํ, inciso XII e, LVI e, Lei no 9.295/96 (Dispõe sobre os Serviços de Telecomunicações e sua organização, sobre o Órgão regulador e, dá outras providências), bem como a Lei $\mathrm{n}^{0}$ 9.296/96 (Regulamenta o inciso XII, parte final, do artigo $5^{\circ}$ da Constituição Federal de 1988).

O artigo $2^{\circ}$ da Lei 9296/96 determina que a Interceptação Telefônica não seja admitida quando a prova puder ser feita por outros meios disponíveis. A Interceptação Telefônica é meio para se chegar à prova do fato investigado.

Concernente à exceção constitucional expressa referir-se somente à Interceptação Telefônica, pode-se entender que não se trata de ser absoluta nenhuma liberdade individual.

Sendo possível, se respeitar certos parâmetros como: interceptação de correspondências, comunicações telegráficas e, de dados sempre que as liberdades públicas estiverem sendo utilizadas como instrumento de salvaguarda de práticas ilícitas. 
Frise-se que a previsão Constitucional, além de esclarecer acerca da inviolabilidade das correspondências, bem como das comunicações em geral, proíbe implicitamente, o conhecimento ilícito de seus conteúdos por parte de terceiros.

Nesse contexto, há uma controvérsia, pois, o Magistrado pode interceptar o telefone do réu com seu advogado, ou seja, o advogado pode ser sujeito passivo da interceptação telefônica?

A corrente majoritária nega essa possibilidade, tendo como base 0 Princípio Constitucional da Ampla Defesa e, o próprio Estatuto da OAB (Lei oㅡ 8.906/94), que em seu artigo $7^{\circ}$, II, está disposto que são direitos do advogado, dentre eles a inviolabilidade de seu escritório, de sua correspondência telefônica, desde que relativas ao exercício da advocacia.

O artigo 154 do Código Penal tipifica o crime de "violação de segredo profissional" e, se o causídico não pode depor acerca do que sabe por causa desse crime o juiz, bem como o Delegado podem responder por tentativa de violação de sigilo profissional, caso não observem esta norma.

Ao se declarar que se trata de ser inviolável o "sigilo da correspondência", bem como das "comunicações telegráficas", como também "de dados e, telefônicas", a Constituição Federal de 1988 proíbe também que se abram cartas e, outras formas de correspondências escritas e, que também se interrompa o seu curso e, se interceptem telefonemas.

Porém, foi aberta excepcional possibilidade de interceptar comunicações telefônicas, por ordem judicial, nas hipóteses e, na forma que a Lei estabelecer para fins de investigação criminal, ou instrução processual.

Dessa forma verifica-se que, mesmo na exceção, a Constituição Federal de 1988 preordenou regras estritas de garantias, para que não se a use para abusos e, que o objeto de tutela é dúplice, ou seja, de um lado, a liberdade de manifestação de pensamento e, de outro, o segredo como expressão do direito à intimidade. 
O que se pode dizer acerca de uma das incontrovérsias da Lei oํ 9.296/96 (Lei da Interceptação Telefônica) é que talvez consista exatamente na inobservância do Princípio da Proporcionalidade.

Concernente à Interceptação Telefônica pode-se afirmar que a realidade social atual é bem distinta da criação e, promulgação da Lei oํ 9.296/96, pois, foram agregados novos mecanismos tecnológicos ao cotidiano das pessoas que eram inexistentes à época da criação.

E, em relação à Interceptação Telefônica, pode-se afirmar que é notória a existência de um conflito Constitucional concernente aos Direitos fundamentais com os interesses do Estado Democrático de Direito.

Pois, a CRFB/88 protege através do que está elencado nos incisos $\mathrm{Xe}$ XII do art. $5^{\circ}$, a "intimidade, a vida privada e, a honra das pessoas", além de sua "comunicação", à época, via postal e telegráfica.

Que, se adequados à realidade corrente, devem ser estendidas às comunicações instantâneas via aplicativos; portanto, não pode ser meio de prova a comunicação entre duas pessoas, porque uma pessoa não pode se autoincriminar.

Porém, o Estado criou um mecanismo de obtenção de prova que veio com o intuito de atingir a "privacidade das pessoas" ao prever a quebra do sigilo telefônico e, tentar reiteradamente, obter junto às Empresas responsáveis o conteúdo das conversas instantâneas via aplicativos.

Para que haja a obtenção da quebra do sigilo telefônico e, ter acesso a conversas privadas de seus usuários, o Estado Democrático de Direito precisou edificar um conjunto de normas que autoriza tal medida e, ao mesmo tempo, teve que criar limitações para essa prática.

Sendo devidamente respeitados os limites para a aplicação da Interceptação Telefônica pode-se relativizar os Direitos fundamentais de uma pessoa, com o intuito de se assegurar a segurança do próprio Estado, bem como de seus componentes, ao coibir as atividades criminosas e, também atentatórias ao ordenamento jurídico nacional. 
E, ainda que exista a excepcionalidade prevista na Constituição Federal de 1988 e, que foi regulamentado pela Lei no 9.296/1996, em que se autoriza a Interceptação Telefônica com seus respectivos requisitos não há impedimento em que a parte que se sentir prejudicada pelo uso de tal mecanismo exerça sua Ampla defesa.

E, o seu direito também ao contraditório, que estão devidamente garantidos após a gravação e, a transcrição, conforme entendimento do Supremo Tribunal Federal (STF) por meio do HC 9233113.

Em relação ao prazo da Interceptação este não poderá exceder o prazo de 15 (quinze) dias e, podendo ser renovável por igual período em caso de comprovada necessidade, como também poderá o juiz autorizar a Interceptação Telefônica por prazo menor.

Portanto, o entendimento do Supremo Tribunal Federal (STF) é de que somente a Interceptação Telefônica e, a escuta telefônica pode ser contempladas pela Lei oㅜ 9.296/1996.

\section{CONCLUSÃO}

Neste trabalho de Pesquisa abordou-se acerca da Interceptação Telefônica e sua Admissibilidade das Provas Produzidas.

E, entendeu-se que a Interceptação Telefônica se trata da gravação de um conteúdo de uma comunicação telefônica e, se dá entre dois, ou mais sujeitos. E, que esta é realizada por uma terceira pessoa sem que os demais sujeitos estejam cientes da captação da conversa.

Em relação aos sujeitos passivos da Interceptação Telefônica a lei não especifica e, poderá ser o indiciado na (fase policial), o réu na (fase judicial) como também a vítima, a testemunha.

Foi vislumbrado também que uma das incontrovérsias em relação à aplicabilidade da Lei oํ 9.296/96 (Lei da Interceptação Telefônica) é que talvez, consista exatamente na inobservância do Princípio da Proporcionalidade quando 
esta referida lei permite a Interceptação Telefônica em relação a todos os crimes punidos com pena de reclusão.

$E$, com isso, não é observado o Princípio da Adequação e da nãoexcessividade, pois, estende a operação técnica indicada para qualquer tipo de crime, desde que, esse crime seja punido com reclusão.

Observou-se ao longo deste trabalho também que a finalidade da Interceptação Telefônica é a obtenção de uma prova, que se materializa num documento, ou depoimento, estando na fase preparatória como também na fase incidental do processo.

Dessa forma, a validade da Interceptação Telefônica, como meio para a obtenção de prova, não prescinde somente da observância aos requisitos que estão contidos na Lei no 9.296/96.

Prescinde também aos Princípios Constitucionais do Devido Processo Legal, da Proporcionalidade, bem como da Inadmissibilidade das Provas Ilícitas, pois, apenas, Regras e Princípios que são Normas Constitucionais possuem a aptidão de fundamentar a restrição a um Direito Fundamental.

E, se a Interceptação Telefônica for utilizada de forma incorreta, ou seja, não expressa na Lei, esta não terá validade jurídica alguma e, desta maneira será considerada ilícita, bem como não obterá êxito algum na obtenção da prova.

Em relação à inadmissibilidade da Interceptação Telefônica esta se dará quando estiverem ausentes indícios razoáveis da autoria como também da participação em infração penal, ou, ainda mesmo, quando a prova puder ser obtida por outras maneiras legalmente previstas.

Sendo assim, é muito importante a indicação concreta de que a reconstrução dos fatos será impossível sem a utilização da Interceptação Telefônica.

É necessário que esteja devidamente fundamentada pelo Juiz. Entendeuse também que o Ministério Público, bem como a autoridade policial, deverá esclarecer acerca das razões pelas quais está sendo realizado o pedido para a liberação da Interceptação Telefônica de alguma pessoa. 
Como também o objeto de tutela é dúplice, ou seja, de um lado, a liberdade de manifestação de pensamento e, de outro, o segredo como expressão do direito à intimidade.

A Lei da Interceptação Telefônica (Lei no 9.296/96) esclareceu como deverão ocorrer as Interceptações telefônicas e, em quais hipóteses serão admitidas essas interceptações, bem como definiu requisitos necessários para sua admissibilidade.

E, ainda que exista a excepcionalidade prevista na Constituição Federal de 1988 e, que foi regulamentado pela Lei no 9.296/1996, em que se autoriza a Interceptação Telefônica com seus respectivos requisitos não há impedimento em que a parte que se sentir prejudicada pelo uso de tal mecanismo exerça sua Ampla defesa.

E, o seu direito também ao contraditório, que estão devidamente garantidos após a gravação e, a transcrição, conforme entendimento do Supremo Tribunal Federal (STF) por meio do HC 9233113.

Em relação ao prazo da Interceptação este não poderá exceder o prazo de 15 (quinze) dias e, podendo ser renovável por igual período em caso de comprovada necessidade, como também poderá o juiz autorizar a Interceptação Telefônica por prazo menor.

Portanto, pode-se afirmar, então, que a finalidade da Interceptação Telefônica é a de ser utilizada para os fins de investigação criminal, ou, instrução processual Penal, como dispõe a Constituição Federal de 1988.

\section{REFERÊNCIAS}

ACQUAVIVA, Marcus Cláudio. Dicionário Acquaviva. São Paulo: Imprenta, Rideel, 2016.

BRASIL. Constituição da República Federativa do Brasil de 1988. http://www.planalto.gov.br/ccivil 03/decreto-lei/Del5452.htm. Acesso em 17.08.2020. 
BRASIL. Decreto-Lei № 2.848, de 7 de Dezembro de 1940. Código Penal Brasileiro. Disponível em: http://www.planalto.gov.br/ccivil 03/decretolei/del2848compilado.htm. Acesso em; 19.08.2020.

CABETTE, Eduardo Luiz Santos. Interceptação telefônica. 3ª ed. São Paulo: Saraiva, 2015.

CAPEZ, Fernando. Curso de Direito Penal 2: Parte Especial (arts. 121 a 212), volume 2 São Paulo: Saraiva, 2019.

CERQUEIRA, Thales Tácito Pontes Luz de Pádua. Interceptação Telefônica. Disponível em: http://bdjur.stj.jus.br/dspace/handle/2011/44769. Acesso em: 15 ago. 2020.

GOMES, Luiz Flávio; MACIEL, Silvio. Interceptação telefônica: comentários à Lei 9.296/96, de 24.07.1996. 3aㅡ ed., ampl. e atual. São Paulo: Saraiva, 2015.

GOMES FILHO, Antônio Magalhães. A Inadmissibilidade das Provas Ilícitas no Processo Penal Brasileiro. Revista Brasileira de Ciências Criminais. Revista dos Tribunais, ano 18, no 85, p. 393- 410, jul.-ago. 2010.

GONÇALVES, Antônio Baptista. Lei de Interceptação Telefônica - Proteção à Conversa do Advogado com o Cliente. Revista Síntese Direito Penal e Processual Penal Nota: Continuação da Revista IOB de Direito Penal e Processual Penal, v. 19, n. 114, fev-mar. 2019.

GRECO FILHO, Vicente. Interceptação Telefônica: Considerações sobre a Lei no $\underline{\text { 9.296 }}$, de 24 de julho de 1996. 3a ed. São Paulo, Saraiva, 2015.

GRECO FILHO, Vicente. Interceptação Telefônica. 3ª ed. São Paulo: Saraiva, 2015.

GRINOVER, Ada Pellegrini. Liberdades Públicas e Processo Penal: As Interceptações Telefônicas. $2^{a}$ ed. São Paulo: Revista dos Tribunais, 1982.

MORAES, Alexandre de. Direito Constitucional, 34로 ed. São Paulo: Saraiva, 2018.

PIRES; GARAY. Apontamentos acerca da validade da Interceptação Telefônica como meio de Obtenção de Prova no Processo Penal: O Entendimento dos Tribunais Superiores e as Propostas de Alteração Legislativa. Revista da Faculdade de Direito UFPR, n. 57, p. 245-267, 2013.

SILVA, José Afonso Da. Curso de Direito Constitucional Positivo. São Paulo: Malheiros, 42 $2^{\mathrm{a}}$ ed., 2019. 